Licença CC BY: Artigo distribuído sob os termos Creative Commons, permite uso e distribuição irrestrita em qualquer meio desde que $o$ autor credite a fonte original.

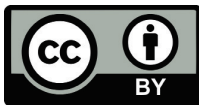

\section{A RELEVÂNCIA DO USO DE SMARTPHONES DURANTE A EXPERIÊNCIA TURÍSTICA}

\author{
THE RELEVANCE OF USING SMARTPHONES DURING THE \\ TOURISM EXPERIENCE
}

LA RELEVANCIA DEL USO DE SMARTPHONES DURANTE LA
EXPERIENCIA TURÍSTICA

JULIANA ROSSI'

UNIVERSIDADE DO ALGARVE, ALGARVE, FARO, PORTUGAL

CÉLIA M.Q. RAMOS 2

UNIVERSIDADE DO ALGARVE, ALGARVE, FARO, PORTUGAL

DATA DE SUBMISSÃO: 15/01/2019 - DATA DE ACEITE: 02/06/2019

RESUMO: Atualmente, para os turistas, os smartphones são imprescindíveis para a realização de uma viagem, quer para procurar informação, quer para comunicar com os amigos e os familiares, neste sentido, o presente artigo pretende investigar a importância dos smartphones para a experiência associada à viagem turística. Foi elaborado e aplicado um questionário on-line, com o objetivo de averiguar a opinião dos utilizadores de smartphones sobre a importância deste tipo de tecnologia e de que forma é utilizada. Após recolha dos dados, procedeu-se à sua limpeza e verificação para detetar as respostas válidas; em seguida, foram aplicadas as ferramentas de Business Intelligence integradas no Microsoft Excel. Como resultados, obteve-se que os turistas consideram relevantes a utilização destes dispositivos, que os utilizam preferencialmente para consultar informações sobre o destino turístico e pontos de interesse, bem como a rede social que mais utilizam é o TripAdvisor.

PALAVRAS-CHAVE: Comportamento do Consumidor; Experiência Turística; Smartphone; Tecnologia de Informação e Comunicação; Turismo.

ABSTRACT: For tourists, Smartphones are now essential for a trip, whether to search for information or to communicate with friends and family. This article investigates the importance of smartphones to the experience associated with the tourist trip. An online questionnaire was developed and applied, seeking to ascertain the opinions of smartphone users about the importance of this type of technology and how it is used. The data gathered were cleaned and verified to detect the valid answers, then the Business Intelligence tools integrated with Microsoft Excel were applied. The results showed that tourists consider the use of these devices important, and use them mainly to search for information on the tourist destination and points of interest. It was also found that the social network most used by tourists is TripAdvisor.

1 Mestranda em Turismo na Escola Superior de Gestão, Hotelaria e Turismo (ESGHT) da Universidade do Algarve, Faro, Portugal. E-mail: julianarossi.sp@gmail.com

2 Professora de Sistemas e Tecnologias de Informação na Escola Superior de Gestão, Hotelaria e Turismo da Universidade do Algarve, Faro, Portugal. Doutora em Métodos Quantitativos aplicados à Economia e à Gestão pela Universidade do Algarve, Faro, Algarve, Portugal. E-mail: cmramos@ualg.pt. Orcid: 00000002-3413-4897 
Rev.Tur., Visão e Ação, v21, n3, p265-290, Set./Dez. 2019 - Balneário Camboriú, Santa Catarina, Brasil

KEYWORDS: Consumer Behavior; Information and Communication Technology; Smartphone; Touristic Experience; Tourism.

RESUMEN: En la actualidad, para los turistas, los teléfonos inteligentes son esenciales para un viaje, ya sea para buscar información o para comunicarse con los amigos y familiares, en este sentido, el presente artículo pretende investigar la importancia de los teléfonos inteligentes para la experiencia asociada con el viaje turístico. Se desarrolló y aplicó un cuestionario en línea con el objetivo de conocer la opinión de los usuarios de teléfonos inteligentes sobre la importancia de este tipo de tecnología y cómo se usa. Después de recopilar los datos, se limpiaron y verificaron para detectar las respuestas válidas, luego se aplicaron las herramientas de Business Intelligence integradas en Microsoft Excel. Como resultado, se obtuvo que los turistas consideran relevante el uso de estos dispositivos, que los utilizan más para consultar información sobre el destino turístico y los puntos de interés, así como la red social que más usan es TripAdvisor..

PALABRAS CLAVE: Comportamiento del consumidor; Experiencia Turística; Smartphone; Tecnología de la información y la comunicación; Turismo.

\section{INTRODUÇÃO}

Desde o lançamento do primeiro dispositivo móvel, na década de 80 (Ugarkar, 2010), que o uso de telemóveis e de smartphones, combinados com o acesso à rede de internet móvel, cresceu vertiginosamente e potencializou atividades comuns como: praticar esportes, cozinhar, ler, pesquisar na mobilidade. (Net//Scope, 2018). Cada vez mais completos e multifuncionais, os smartphones amplificaram suas funções de uso. Todos os dias novas aplicações são desenvolvidas e o impacto dos smartphones na vida das pessoas é cada vez maior (Dias, 2007).

De forma a proporcionar serviços mais acessíveis e atraentes, sejam para residentes como para visitantes, além de contribuírem para o desenvolvimento de serviços interativos que possibilitam que as pessoas acedam rapidamente serviços e informações, as aplicações ganham espaço por incorporar tecnologia no dia a dia. Em grandes centros urbanos, muitas pessoas utilizam seus smartphones para melhorar sua qualidade de vida, como: saber os horários dos autocarros (Françozo \& De Mello, 2016); serviços bancários (De Oliveira, \& Malagolli, 2016); fluxo do trânsito (Trovo, Artero, Piteri, \& da Silva, 2014); qual o melhor caminho para chegar à casa, visto que uma melhor mobilidade tem impactos positivos na qualidade de vida e nos níveis de stress (Lemos, 2017). Mas não é somente na mobilidade que se pode destacar a importância dos smartphones. Eles também podem proporcionam melhor controle das atividades físicas, por meio de aplicações que encorajam a prática de esportes e avaliam o desempenho; também permitem explorar as cidades de formas diferentes, mais interativas e criativas, o que potencializa o uso dos smartphones não só no cotidiano, mas na atividade turística procurando contribuir, enriquecer e melhorar a competitividade dos destinos turísticos (Pereira, Dos Santos, Merino, Braviano, \& Colusso, 2018). 
Além do já mencionado, os recursos disponíveis nos smartphones proporcionam um contato diferente no relacionamento com o consumidor, criam oportunidades baseadas na comunicação e na interação durante a experiência turística (Biz, Neves, \& Bettoni, 2014). De acordo com o relatório Future Traveller Tribes 2030 (Amadeus, 2015), Understanding Tomorrow Traveller, publicado pela Amadeus Traveller Trend Observatory, em abril de 2015, as tendências de viagem nos próximos anos devem estar muito ligadas à utilização acentuada das tecnologias; aos critérios sociais, culturais, falta de tempo; à facilidade na gestão da viagem e deslocamento e ao luxo/ostentação. De acordo com Parasuraman e Colby (2002), a inclinação das pessoas para o uso da tecnologia é uma combinação de crenças que pode apontar uma predisposição para interagir com produtos e serviços baseados em tecnologia e, eventualmente, pode vir a assinalar o uso de novas tecnologias para alcançar metas em casa e no trabalho.

O smartphone é realmente um fenómeno global e, no caso da atividade turística, o uso de dispositivos móveis está a influenciar todas as etapas do ciclo de vida da experiência turística. De acordo com a Travel Tech Consulting (2019), o uso de smartphones ultrapassa $50 \%$ nos EUA e na Europa, com a adoção crescente e rápida nos mercados emergentes. Os dispositivos móveis atingiram o mainstream, com implicações de grande alcance para a estratégia de viagem. Mas qual a relevância do uso de smartphones na experiência turística?

Os smartphones e as suas aplicações contribuem para ajudar os viajantes desde possibilitar o acesso a informações em qualquer lugar e a qualquer hora (Wang, Park, \& Fesenmaier, 2012), contribuir para complementar as atividades realizadas durante a viagem (Tussyadiah \& Fesenmaier, 2009), uma vez que podem contribuir para o surgimento de novas oportunidades "sociais" e "locais" que contribuem para acrescentar valor à experiência turística. Os autores Dickinson, Ghali, Cherrett, Speed, Davies, \& Norgate (2014) realizaram uma análise às aplicações disponíveis nos smartphones, utilizadas em contexto de viagem turística, onde concluíram que estes dispositivos móveis têm um papel fundamental no processo de tomada decisão, tornando a viagem mais dinâmicas, colaborativa e sustentável.

De acordo com Wang, Xiang e Fesenmaier (2016), os smartphones já são tão usados no dia a dia, que a sua utilização durante uma viagem é uma peça essencial do turista durante a sua viagem. Yu, Anaya, Miao, Lehto e Wong (2018) reforçam que os smartphones podem melhorar a interação e a coesão familiar durante uma viagem. Contudo, para estes autores, ainda existe um vazio na compreensão do papel que os smartphones têm na dinâmica de interação e relacionamento durante as férias, apesar de concluírem que promovem um senso de unidade dentro do grupo; enquanto mantém a individualidade, contribuem para criar e guardar memórias associadas à viagem, o que resulta num contributo positivo e duradouro da experiência turística.

Nesse sentido, pretende-se verificar quais valores experienciais, de acordo com a vivência dos utilizadores inquiridos, que mais influenciam no uso dos 
Rev.Tur., Visão e Ação, v21, n3, p265-290, Set./Dez. 2019 - Balneário Camboriú, Santa Catarina, Brasil

smartphones na atividade turística. Para tanto, foi realizada uma pesquisa online, de caráter metodológico quantitativo, por meio da qual foram levantadas informações sobre os principais usos dos smartphones em viagens e recursos. $O$ inquérito foi respondido por 245 pessoas, no mês de maio de 2017 e foi analisada a satisfação em relação à experiência turística. As fontes de pesquisa foram variadas, incluindo fontes bibliográficas, periódicos, artigos e a internet.

Face ao exposto, o objetivo geral de investigação deste artigo é analisar as características dos utilizadores que mais influenciam o uso de smartphones, a relevância do seu uso durante uma viagem turística, a influência que os comentários consultados on-line têm para o processo de tomar a decisão sobre o que visitar, bem como a ação mais realizada por meio do smartphone durante uma viagem, com o objetivo de contribuir para o desenvolvimento da atividade turística, que vá ao encontro das expetativas do turista, e para a gestão dos destinos turísticos, com vista a adequar a oferta às preferências dos visitantes, uma vez que os smartphones representam um acréscimo de valor para o turismo, uma vez que permite a troca de opiniões, experiências e imagens inspiradoras para outros viajantes, contribuindo para a divulgação do destino, enquanto apoia o turista no processo de tomada de decisão a quando do planeamento da sua viagem.

O artigo está dividido em três secções: revisão de literatura, metodologia e avaliação dos resultados que procuram explorar os pontos indicados que contribuem para investigar o objetivo proposto no presente estudo.

\section{FUNDAMENTAÇÃO TEÓRICA - MÍDIAS E TECNOLOGIAS NO TURISMO}

O turismo é um setor em constante crescimento e o avanço das tecnologias tem contribuído para transformar a experiência de viagem das pessoas. Os dispositivos móveis ganham cada vez mais destaque, como um bem essencial para realizar uma viagem turística. Os smartphones proporcionam ao turista uma série de experiências de áudio, vídeo, textos e imagens, jogos, ferramentas e aplicativos (apps) que proporcionam acesso à informação em tempo real. De acordo com a presidente do Amadeus, Julia Sattel:

"O mobile é uma força imparável que está configurada para transformar a experiência do viajante. Enquanto o celular não é amplamente utilizado para geração de receita hoje, o canal é, sem dúvida, a maneira mais íntima e flexível de interagir com um cliente." (Rose, 2011).

Os turistas precisam de informações para tomar decisões sobre a escolha e o planeamento do destino de viagem. Os meios de comunicação, mais especificamente a mídia no turismo, tem uma importância muito grande nesse processo, pois trabalham o imaginário do público-alvo para que, a partir de então, ocorra o consumo. E com a globalização, as pessoas ao redor 
do mundo recebem muito mais informações e conhecimento dos produtos turísticos, fazendo com que a escolha do cliente e dos desejos enfrente grande concorrência de mercado e mudanças contínuas para atender um público cada vez mais vulnerável às mudanças (guerras, terrorismo, declínio de um destino, insegurança, tendências do turismo, etc.).

Uma pesquisa feita pelo TripAdvisor (Ministério do Turismo, 2015) reforça a ideia de que os smartphones são cada vez mais usados pelos turistas, quer seja para planear ou para reservar uma viagem. Segundo a mesma pesquisa, os brasileiros estão entre os que mais usam o smartphone para viajar (posicionamse atrás da China e da Tailândia) (Braga, 2015). Ou seja, a tecnologia atende as necessidades dos turistas ao mesmo tempo em que cria novas oportunidades de emprego, promove o desenvolvimento de novos produtos e agrega valor. Segundo Guimarães e Borges (2008):

"O setor do turismo é um grande incorporador de tecnologia, nos seus diversos segmentos, e o seu crescimento sempre depende da capacidade de inovação e do uso da tecnologia para melhoria de gestão, desenvolvimento de novos produtos, aperfeiçoamento da comunicação, otimização das experiências de viagens e personificação do atendimento (Guimarães e Borges, 2008, p.10)".

De acordo com o Turismo 2020, os smartphones se popularizaram rapidamente, alterando a forma de se comunicar com o turista antes, durante e depois da viagem (Turismo 2020, 2015). O setor do turismo se mostra cada vez mais atrativo para a economia digital, sharing economy, big data e mobile. Não é casual que uma das diretrizes do Turismo 2020 é o reforço de presença no digital e aposta no mobile para responder aos desafios da dinamização de plataformas web interativas e das redes sociais, favorecendo uma estratégia de digitalização como aposta nos canais on-line e mobile. Além disso, a estratégia pretende fomentar a interação com o turista e introduzir uma filosofia participativa e colaborativa de co-criação por parte dos turistas (Turismo 2020, 2015). Um dos maiores exemplos de filosofia participativa é o Waze (2019), aplicação de trânsito que, além sua função principal - indicar a melhor rota -, promove entreajuda entre condutores por meio da partilha de informações de trânsito em tempo real.

O canal mobile, por meio dos aplicativos, cada vez mais especializados, é uma tendência positiva e que se manterá nos próximos anos. Segundo - Google, o novo comportamento dos utilizadores de dispositivos móveis modificou a forma como o viajante faz as suas compras (Pegn, 2016). Os consumidores utilizam os "micro-momentos" (quando buscam informações em meio a outras tarefas) para pesquisar, planear, reservar, comprar e compartilhar suas viagens. Cada vez mais o mercado de viagens e lazer está on-line e a tendência é crescer mais ainda. Os meios tradicionalmente off-line estão atentos e vão transitando as suas atividades para o on-line. As grandes agências e operadores estão neste caminho, embora sempre haja clientes que preferem o atendimento personalizado, seja por telefone ou face-fo-face. 
Rev.Tur., Visão e Ação, v21, n3, p265-290, Set./Dez. 2019 - Balneário Camboriú, Santa Catarina, Brasil

De acordo com um estudo feito pela Hitwise (2016), em 2016, com foco no mercado britânico, foi efetuada uma análise do perfil de mais de 3 milhões de consumidores e cerca de $60 \%$ das procuras foram relacionadas com o turismo por meio de dispositivos móveis (ver Figura 1 - viagens). Ainda segundo o mesmo estudo, as pesquisas iniciadas em dispositivos móveis têm o papel principal de responder às principais dúvidas dos consumidores antes da compra.

Os smartphones são ferramentas chave para os viajantes (Hitwise, 2016). A pesquisa feita pela Hitwise divulgou a percentagem de pesquisas relacionadas com o turismo, iniciadas em dispositivos móveis de acordo com o interesse ou área (ver Figura 2). A personalização dos dispositivos móveis, a flexibilidade de uso (em qualquer lugar, a qualquer hora e qualquer tipo de informação) e a disseminação (em função das ligações que permitem compartilhar informações) são as características mais relevantes da tecnologia móvel (Kim, Park, \& Morrison, 2008).

Figura 1 - Pesquisas on-line iniciadas por dispositivo móvel (por indústria).

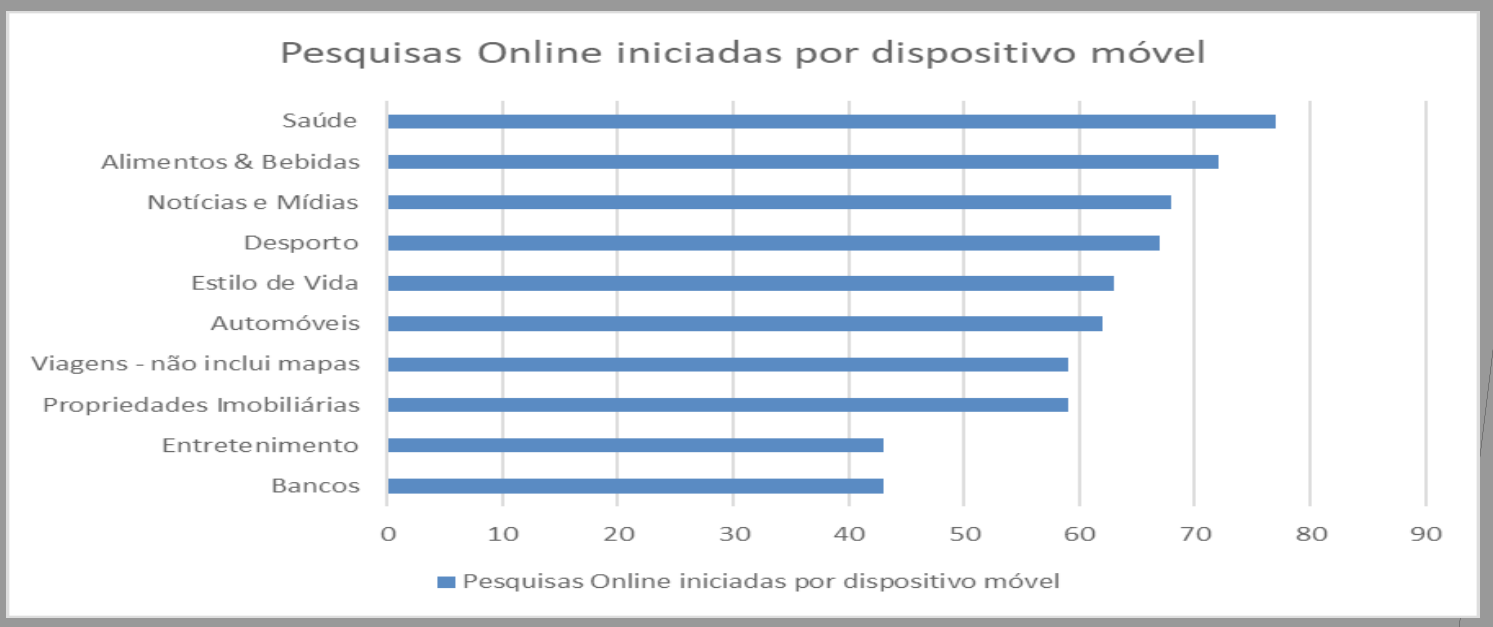

Fonte: Adaptado de Hitwise (2016). 


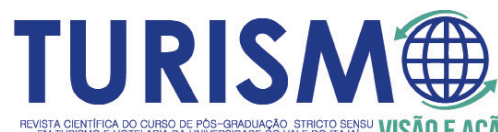

Figura 2 - Percentagem de temas de pesquisa de viagem iniciadas por meio de dispositivos móveis.

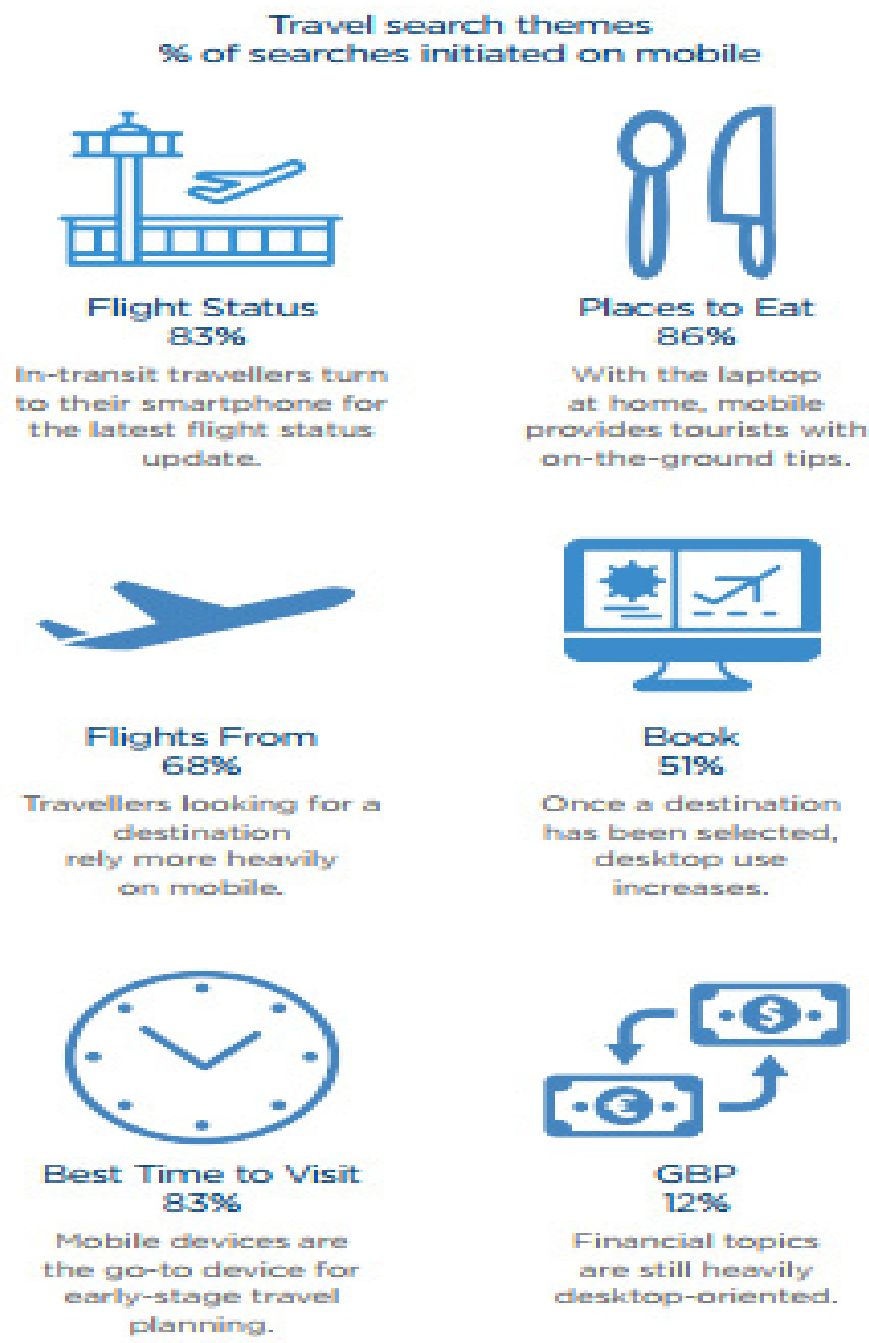

Fonte: Hitwise (2017).

De acordo com pesquisa semelhante, realizada pelo Google em 2014 (Google Travel Study, 2014), nos Estados Unidos, a utilização da internet cresceu como fonte de informação e de pesquisa. Muitas das pesquisas iniciadas nos smartphones e nos tablets são as mesmas iniciadas em computadores e, muitas vezes, o telemóvel representa ainda um volume maior de pesquisas (ver Figura 3). 
Rev.Tur., Visão e Ação, v21, n3, p265-290, Set./Dez. 2019 - Balneário Camboriú, Santa Catarina, Brasil

Figura 3 - Tipos de Sites visitados por Viajantes por Meio Dispositivos Móveis.

Travelers go to the same types of sites on smartphones as they do on desktop/tablet ... and sometimes more so

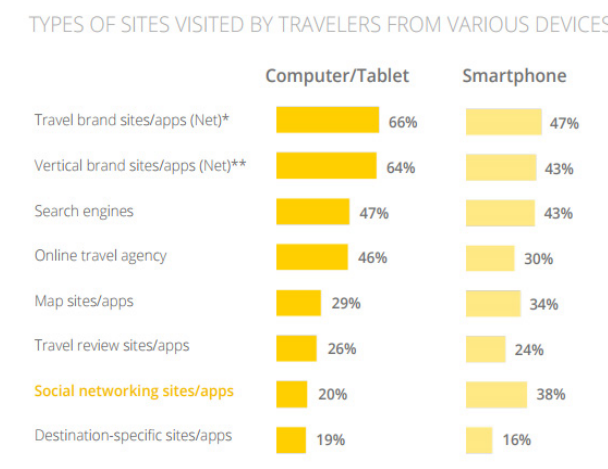

Fonte: Google Travel Study, 2014.

Ainda de acordo com a pesquisa realizada pelo Google (Google Travel Study, 2014), cerca de $38 \%$ das pessoas utilizam os smartphones para concretizar a reserva (ver Figura 4). Os dispositivos móveis estão cada vez mais presentes na vida das pessoas e possibilitando novas formas de interação com as agências de viagens e operadores turísticos. No entanto, uma experiência negativa associada à utilização de smartphone pode ter efeito contrário ao pretendido e prejudicar a imagem do website visitado.

A experiência com os dispositivos móveis é muito pessoal. Quando se trata de iniciativas e criação de aplicativos, os utilizadores propõem-se a deixar comentários e feedbacks de acordo com sua experiência. Caso o aplicativo ou o site seja um exemplo de boas práticas e interação, o sucesso é da mesma forma garantido e a informação passa adiante, de acordo com o estudo da Ynooz (Loller, 2012).

O fato é que o consumidor atual tem o que quer na hora em que deseja, pelo menos no que se refere à informação. Os smartphones proporcionam acesso instantâneo ao que o cliente busca. Como resultado desse imediatismo, o cliente é cada vez mais exigente, o que conduz às altas expectativas, principalmente no que se refere ao atendimento. Segundo Torres (2018), os turistas querem sentir-se confiantes e são muitas as ferramentas de pesquisa que ele precisa utilizar antes de realizar a tomada de decisão associada à compra. 
Figura 4 - Métodos de reserva após o uso de smartphones como inspiração para viagens de lazer

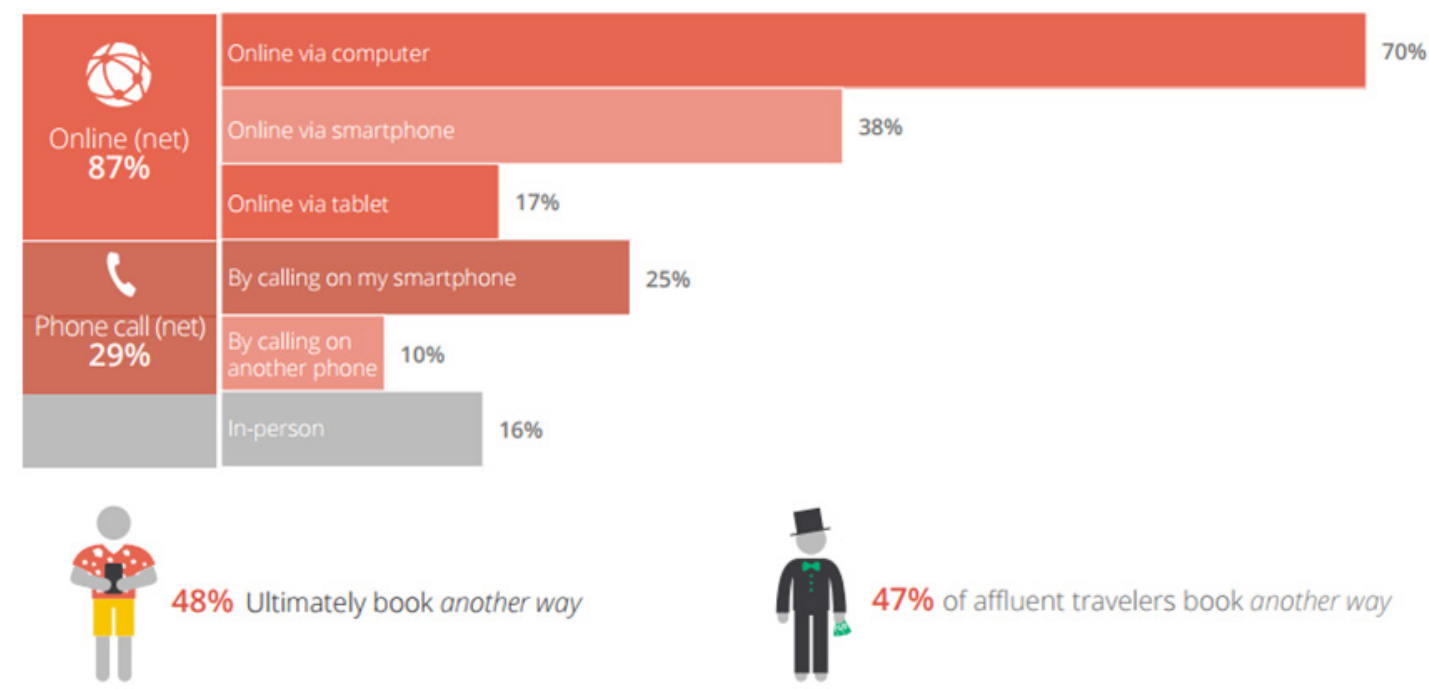

Fonte: Google Travel Study, 2014.

Apenas para complementar o gráfico, vale ressaltar que $47 \%$ dos viajantes escolhem outras formas de fazer a reserva e $48 \%$ dos viajantes de luxo/ mais ricos escolhem outros caminhos para concretizar a reserva.

Uma empresa paulista, o Dubbi (2019), tem a proposta de tirar dúvidas do viajante de forma personalizada e de acordo com suas preferências. A intenção, neste caso, é dar um toque humano e oferecer informações que agentes de viagens e grandes veículos muitas vezes não conseguem. O canal utilizado é uma rede colaborativa. Por meio desta tecnologia, a aplicação encontra os viajantes mais aptos para responderem determinadas dúvidas. As respostam são avaliadas e as mais positivas ficam em destaque. A monetização ocorre por intermediação de produtos e serviços de viagens para leads qualificados, pois segundo a empresa, $75 \%$ de seus usuários compram de acordo com as dúvidas tiradas na internet. Esse é um exemplo do aumento da oferta e do acesso à informação no atual mundo on-demand que, acelerado pela tecnologia, permite maior espontaneidade e busca pontual pelo interesse, com informações mais fidedignas de quem viveu a experiência. Esse tipo de interação é o que pode levar o cliente, que está cada vez mais exigente neste segmento, a aproveitar promoções, fazer viagens em last minute, viajar mais vezes ao ano, especialmente em viagens curtas, que é uma tendência, de acordo com Torres (2018). Segundo Prado (2018), as empresas que se destacam são as que ajudam o cliente a tomar melhores decisões e mais de acordo com as suas preferências.

\section{SMART TRAVEL}

Segundo o relatório anual da World Travel Market (Bremner \& Nelson, 2015), a tecnologia e o uso de ferramentas que proporcionam a personalização 
Rev.Tur., Visão e Ação, v21, n3, p265-290, Set./Dez. 2019 - Balneário Camboriú, Santa Catarina, Brasil

das viagens remetem ao conceito smart travel ou viagem inteligente. Esse conceito refere-se ao uso da internet para personalizar e executar a viagem, principalmente por meio dos dispositivos móveis (tablets e smartphones). O uso de dispositivos móveis para reservas representou, em 2014, cerca de 96 bilhões de dólares em vendas globais (Bremner \& Nelson, 2015), empresas como Google, Facebook, Apple e TripAdvisor, que são grandes concentradores de informações específicas de cada usuário de internet e podem criar ferramentas e soluções de acordo com seu conhecimento (Bremner \& Nelson, 2015).

Portanto, a personalização das viagens ganha cada vez mais espaço no mercado, especialmente com os Millenials (Veiga, Santos, Águas, \& Santos, 2017). Também conhecidos como geração internet, são jovens nascidos entre o início dos anos 80 e o início do ano 2000 e que, superexpostos à tecnologia, consomem de uma forma diferente. São pioneiros nos usos de tecnologias e estão sempre conectados (Jenkins, 2008). Os Millenials preferem viajar para destinos urbanos, preferem viagens em grupo, fazem muitas fotos e vídeos, compartilhando-os em redes sociais (Facebook, Instagram, Snapchat, entre outras) e fazem comentários sobre a experiência de viagem nas redes sociais (Veiga et al., 2017).

De acordo com a diretora de pesquisa em viagens e turismo da Euromonitor International, Caroline Bremner, o turismo é uma das atividades mais importantes na internet e a popularização da internet representa uma grande oportunidade de negócios (Bremner e Nelson, 2015). Nesse sentido, o Reino Unido se destaca como destino, em especial nas regiões menos visitadas, como o norte da Inglaterra. Este fenómeno ocorre devido às estratégias implementadas pelas empresas de tecnologia que têm estado a desenvolver soluções para atrair visitantes. Essas soluções podem ser aplicativos para tablets/smartphones ou jogos on-line que procuram transformar a experiência urbana para residentes e turistas negócios (Bremner \& Nelson, 2015).

Há também uma iniciativa por parte do governo chamada Smart City, onde a tecnologia digital está inserida em uma cidade para tornar a vida urbana mais eficiente e, consequentemente, pode afetar o turismo, melhorando o transporte, a acessibilidade e as instalações. Para Geoff Nelson, diretor de estratégia de Milton Keynes (Arup, 2013):

"As iniciativas Smart City já aumentaram os visitantes de Milton Keynes, especialmente os turistas empresariais e governamentais que desejam aprender sobre a implementação de tecnologia na prática. As visitas de lazer domésticas e internacionais também estão suscetíveis ao crescimento no futuro devido ao perfil reforçado da cidade em atrações de tecnologia, como carros sem motor." (Traduzido de Arup, 2013).

A iniciativa Smart City foi implementada em Bristol, Cambridge, Glasgow e Milton Keynes. O projeto pretende contribuir para que as cidades se diferenciem de seus concorrentes, oferecendo aplicativos de tecnologia para ajudar os visitantes a aproveitar o máximo da cidade durante sua permanência 
(Arup, 2013). No caso de Portugal, Lisboa caminha para se tornar uma smart city e não necessariamente por ser extremamente high tech, pelos projetos em que procura colocar a tecnologia a serviço dos cidadãos. No Bairro da Boa Vista, a cidade de Lisboa implementou um dos primeiros projetos de smart governance. A autarquia, em conjunto com associações locais, procura regenerar o bairro e, também, promover treinamentos, evitando assim o abandono escolar. De acordo com Pedro Grilo para o Jornal Público (2017): "a própria comunidade, através das suas associações - de residentes e de âmbito social, cultural e ambiental - colabora nessa regeneração do seu bairro".

Os smartphones e as suas aplicações contribuem para ajudar os residentes, para além dos turistas, os quais permitem o acesso a informações em qualquer lugar e a qualquer hora (Wang et al., 2012), bem como permitem a criação de redes de colaboração entre utilizadores que possibilitam a oferta e a divulgação de serviços locais, que contribuem para a economia das populações e para a sustentabilidade dos destinos (Dickinson et al., 2014), ou seja, para o surgimento de novas oportunidades "sociais" e "locais (Tussyadiah \& Fesenmaier, 2009), que acrescentam valor à experiência turística.

Para além de contribuírem para a experiência turística dos turistas, da sustentabilidade dos destinos e devido às suas características que permitem um ambiente colaborativo (Christino, Silva, Cardozo \& Lopes, 2019), permitem melhorar a interação e a coesão familiar durante todas as etapas de uma viagem (Yu et al., 2018), que reforçam um sentido de união dentro do grupo familiar, que contribui para o bem-estar dos viajantes, enquanto mantêm a sua individualidade e vão ao encontro das suas preferências, bem como são um suporte para gestão e manutenção das memórias associadas à experiência turística.

Os smartpones durante uma viagem são relevantes para procurar informação sobre os destinos, e a interação com estes dispositivos permite o acesso à informação contextual e tendo em conta a localização do turista (Gretzel, 2011). Para além da importância durante a vigem, são utilizados em diferentes facetas da vida diária (Wang et al., 2014) por todas as pessoas, inclusive alterou o comportamento dos consumidores, que cada vez compram mais produtos na internet (Xiang, Magnini, \& Fesenmaier, 2015a) mesmo em tempos de crise (Cruz Vareiro \& Sousa Pinheiro, 2017).

\section{METODOLOGIA}

No presente trabalho a metodologia considerada foi constituída por um conjunto de passos: (a) enquadramento teórico, realizado a partir da leitura de trechos de livros, artigos, jornais, bases de dados e o acesso à web; (b) elaboração do questionário divulgado on-line para possibilitar o estudo do objetivo proposto nesta investigação; (c) recolha e tratamento de dados; (d) tratamento e análise dos dados com ferramentas de Business Intelligence, a saber Power Pivot e Power View da Microsoft. 
Rev.Tur., Visão e Ação, v21, n3, p265-290, Set./Dez. 2019 - Balneário Camboriú, Santa Catarina, Brasil

\section{Objetivos da InVEStigação}

O objetivo da investigação é analisar a relevância do uso do smartphone durante uma viagem turística e o seu contributo para a experiência turística.

\section{QUESTIONÁRIO}

O questionário foi construído em torno de dois temas principais: a caracterização dos inquiridos e a relevância da utilização do smartphone durante as etapas de uma viagem turística. No que se refere ao segundo tema, foram definidas as seguintes perguntas de investigação: (i) Qual a relevância da utilização de smartphones durante uma viagem turística? tendo base o trabalho de Wang et al. (2016); (ii) Qual a influência da utilização dos comentários sobre a viagem colocados e consultados na internet na escolha de um destino ou de uma opção de alojamento ou de visita a um ponto turístico? tendo base o trabalho de Xiang, Wang, O'Leary \& Fesenmaier (2015b); (iii) Qual a principal ação que realiza com recurso à tecnologia durante a viagem?, como abordado por Gretzel (2011); (iv) Qual a rede social mais utilizada? (Xiang \& Gretzel, 2010).

\section{FICHA TÉCNICA DA AMOSTRA}

A ficha técnica, apresentada a seguir, identifica as características do estudo sobre a forma como o inquérito foi divulgado, sobre a recolha de dados e sobre a taxa de respostas válidas.

\begin{tabular}{|l|l|}
\hline Universo & $\begin{array}{l}\text { Utilizadores de Smartphones durante uma viagem } \\
\text { turística }\end{array}$ \\
\hline Tamanho da amostra & 242 questionários válidos, dos 245 recolhidos \\
\hline $\begin{array}{l}\text { Método de obtenção } \\
\text { de dados }\end{array}$ & $\begin{array}{l}\text { Inquérito por via de questionário on-line, distribuído } \\
\text { por meio da rede social Facebook. }\end{array}$ \\
\hline $\begin{array}{l}\text { Procedimento da } \\
\text { amostra }\end{array}$ & Amostra por conveniência \\
\hline $\begin{array}{l}\text { Aplicação de } \\
\text { inquérito }\end{array}$ & Maio de 2017 \\
\hline
\end{tabular}

\section{Recolha e tRATAMENTO DE DADOS}

O processo de recolha de dados ocorreu no mês de maio de 2017, por meio de questionário divulgado on-line pelos alunos do mestrado em "omitido por questão de confidência do artigo", e elaborado por meio do Google forms, em que foram obtidas 245 respostas que, após o tratamento e a verificação, foram reduzidas a 242 respostas válidas. 
Após validação das respostas, limpeza e tratamento dos dados recolhidos, foi criado o modelo de dados para efetuar uma análise com ferramentas de business intelligence (Santos \& Ramos, 2009) integradas dentro do Microsoft Excel: PowerPivot e Powerview. O modelo de dados apresentado na Figura 5 é constituído por uma tabela de factos, que contêm as medidas associadas às respostas e cinco dimensões que contribuem para caracterizar os inquiridos.

O tratamento de dados foi realizado de forma a obter análises univariadas e bivariadas e de correspondência medindo as relações entre as variáveis (Freitas \&, 2002) com aplicação de técnicas adquiridas em sala de aula por meio do uso das ferramentas PowerPivot e PowerView integradas no Microsoft Excel.

Figura 5 - Modelo de dados associado às respostas do inquérito.

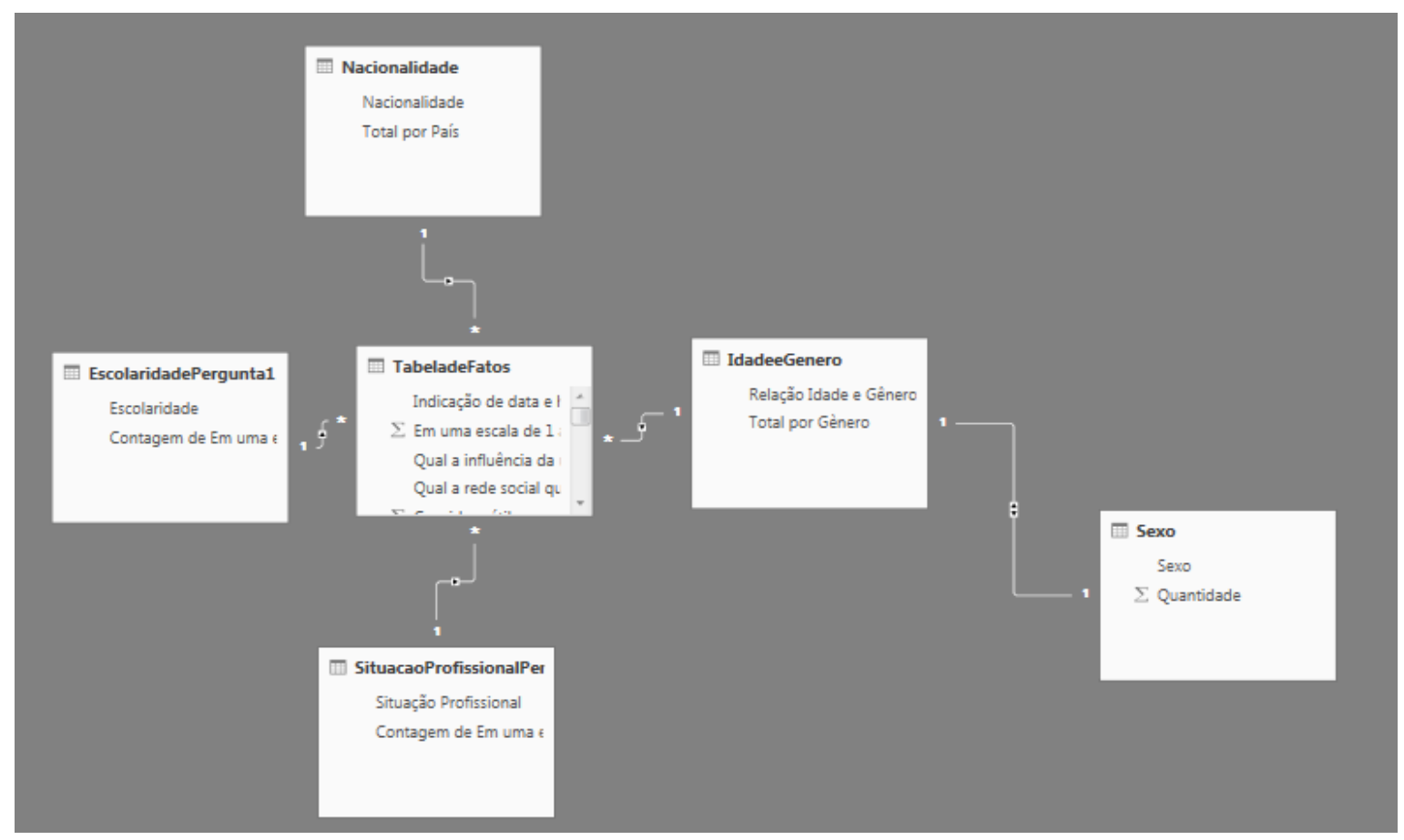

Fonte: Elaboração própria.

\section{RESULTADOS}

\section{Caracterização da AMOstra}

De acordo com os dados obtidos, os inquiridos são na sua maioria de nacionalidade portuguesa e brasileira, tal como apresentado na Figura 6. Dos inquiridos, 134 eram de nacionalidade portuguesa, que representam 55\%; 102 brasileira, que representam 4\%; e as restantes nacionalidades foram contempladas com um inquirido como resposta. 
Rev.Tur., Visão e Ação, v21, n3, p265-290, Set./Dez. 2019 - Balneário Camboriú, Santa Catarina, Brasil

Figura 6 - Nacionalidade dos Inquiridos.

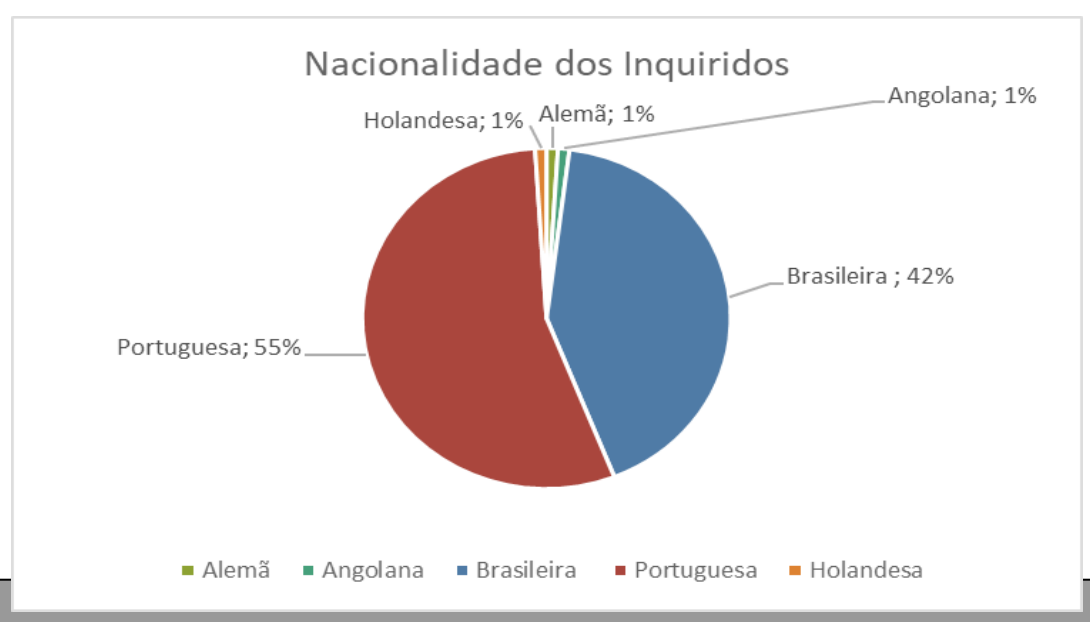

Fonte: Elaboração própria.

No que se refere ao género, a maioria dos inquiridos é do género feminino, com $76 \%$ das respostas (184) e o género masculino, com $24 \%$ das respostas (58). Pode-se dizer que a maioria dos inquiridos é feminina, o que revela que este género interage na internet muito mais do que o público masculino. Embora as mulheres não sejam a maioria na internet, são as maiores influenciadoras no mundo digital, pois passam mais tempo conectadas e interagem mais a comunicar com outros cibernautas. De acordo com pesquisa do Ibope Nielsen Online (2015), no Brasil, $51 \%$ das mulheres passaram a aceder à internet pelo smartphone, no ano de 2015, esses números continuam a crescer. Uma floricultura de São Paulo, Giuliana Flores, realizou uma pesquisa onde comprova que as mulheres que acedem ao site da empresa decidem qual produto que querem e indicam o seu interesse. Os homens acedem ao website e fazem apenas a compra (E-Commerce News, 2012), revelando que cada género tem um comportamento diferente on-line em termos de procura e de aquisição de produtos e de serviços.

Quanto à escolaridade dos inquiridos, a maioria dos inquiridos tem o grau referente à licenciatura, correspondente a 55\% (132 respostas); seguindo-se o ensino secundário, com 19 \% (46 respostas); os detentores do grau de mestre, com 18\% (43 repostas); doutoramento, com 3\% (8 respostas); ensino básico, com 1\% (3 respostas); e os restantes inquiridos são detentores de especializações e outras habilitações, tal como apresentado na Figura 7. Pode-se dizer que o grau de escolaridade entre os inquiridos é alto. 
Figura 7 - N. ${ }^{\circ}$ de Inquiridos por Nível de Escolaridade

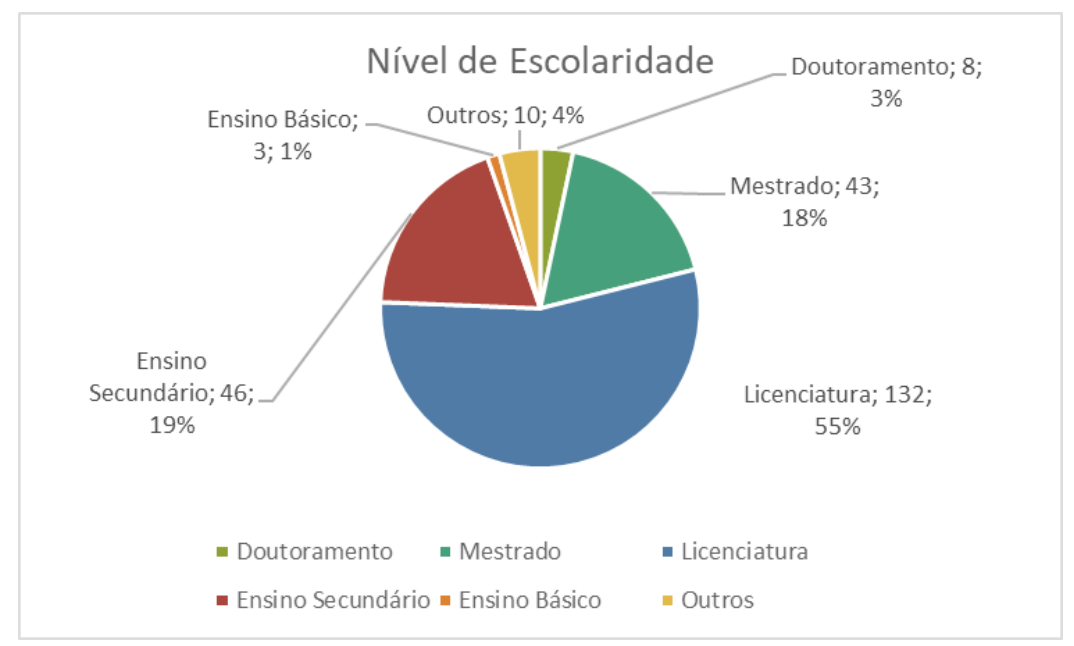

Fonte: Elaboração própria.

No que se refere à situação profissional, a maioria dos inquiridos é "Empregado por conta de outrem referente a 49\% (119 respostas), seguindo-se os "Estudantes", 27\% (65 respostas); "Empregado por conta própria", com 12\% (28 respostas); "Desempregados", com 7\% (17 respostas); "Reformados", com 3\% (8 respostas); e os restantes inquiridos apresentam outras situações profissionais, tal como apresentado na Figura 8.

Figura 8 - N. ${ }^{\circ}$ de Inquiridos por Situação Profissional

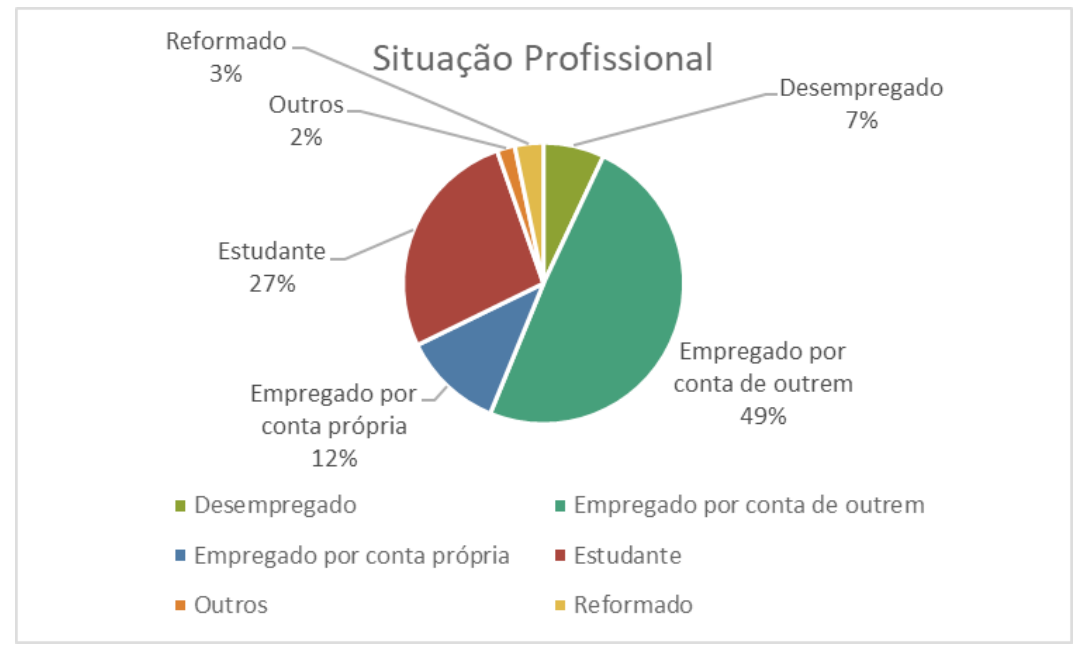

Fonte: Elaboração própria.

RELEVÂNCIA DO USO DE SMARTPHONES

No que se refere à pergunta de investigação, referente à relevância do uso dos smartphones durante uma viagem (experiência turística), em que 1 
Rev.Tur., Visão e Ação, v21, n3, p265-290, Set./Dez. 2019 - Balneário Camboriú, Santa Catarina, Brasil

significa "Nenhuma relevância" e 5 - "Extremamente relevante", a maioria dos inquiridos respondeu "Extremamente importante - 54\% (130 respostas); seguindose "Importante", com 31\% (75 respostas); "Neutro", com 13\% (31 respostas); "Pouco importante", com 2\% (5 respostas);e "Nenhuma importância", com 0\% (0,4 \% - 1 resposta), tal como apresentado na Figura 9.

Cada vez mais as pessoas utilizam a internet em seus smartphones como fonte de informações durante a viagem, bem como para adquirir serviços. A importância atribuída à utilização do smartphone é elevada, o que é explicado quer pela sua utilidade quer pelas suas características, sendo cada vez mais um acessório que faz parte do dia a dia, como um companheiro, quer para o turista encontrar a sua localização, quer para procurar por um restaurante ou para descobrir atrações locais. Por esse motivo, hotéis, restaurantes, etc. tendem, cada vez mais, a marcar presença no espaço on-line de forma a serem encontrados e visualizados pelos viajantes, tal como referido por outros autores na literatura (Braga, 2015; Dickinson et al., 2014; Wang et al., 2012; Wang et al., 2016; Yue † al. , 2018).

Figura 9 - Relevância da utilização do smartphone durante uma viagem turística

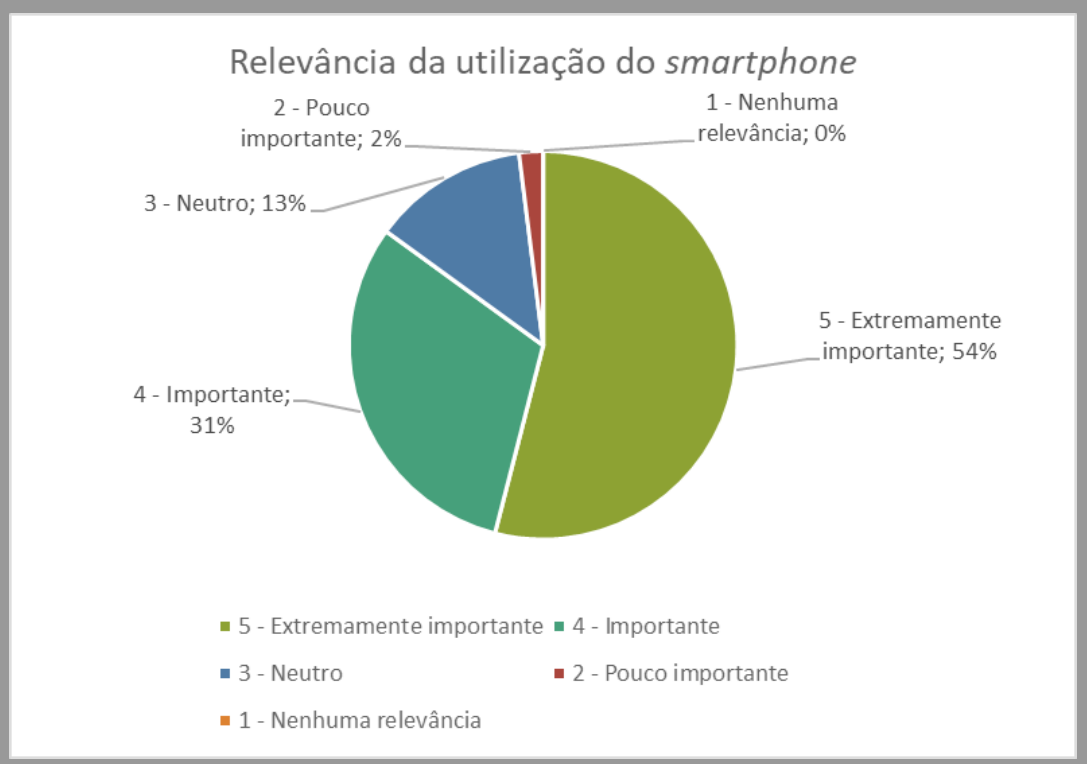

Fonte: Elaboração própria.

No que se refere à importância de utilização dos smartphones durante a viagem, um ponto considerado relevante foi perceber "Qual a influência da utilização dos comentários de viagem, colocados e consultados na internet, na escolha de um destino ou de uma opção de alojamento ou de visita a um ponto turístico?" Ou seja, de que forma a opinião expressa on-line por outros viajantes tem efeitos na tomada de decisão por cada um dos cibernautas.

No que se refere à pergunta de investigação "Qual a influência da utilização dos comentários os de viagem, colocados e consultados na internet, na 
escolha de um destino ou de uma opção de alojamento ou de visita a um ponto turístico?", as respostas podem ser analisadas na Figura 10, que apresenta os três valores percentuais mais altos assinalados referentes às respostas dos inquiridos.

Figura 10 - Qual a influência da utilização de comentários durante uma viagem turística

\begin{tabular}{|l|l|r|r|}
\hline \multicolumn{1}{|c|}{ Relevância do Smartphone } & \multicolumn{1}{|c|}{$\begin{array}{c}\text { Qual a influência da } \\
\text { utilização dos } \\
\text { comentários? }\end{array}$} & No de Inquiridos & No de Inquiridos (\%) \\
\hline $\mathbf{1}$ - Nenhuma relevância & Moderada & 1 & $0 \%$ \\
\hline $\mathbf{2}$ - Pouco relevante & Alta & 1 & $0,4 \%$ \\
\hline $\mathbf{2}$ - Pouco relevante & Extremamente alta & 1 & $0,4 \%$ \\
\hline $\mathbf{2}$ - Pouco relevante & Moderada & 2 & $0,8 \%$ \\
\hline $\mathbf{2}$ - Pouco relevante & Pouca & 1 & $0,4 \%$ \\
\hline $\mathbf{3}$ - Neutro & Alta & 17 & $7,0 \%$ \\
\hline $\mathbf{3}$ - Neutro & Extremamente alta & 1 & $0,4 \%$ \\
\hline $\mathbf{3}$ - Neutro & Moderada & 11 & $4,5 \%$ \\
\hline $\mathbf{3}$ - Neutro & Nenhuma & 1 & $0,4 \%$ \\
\hline $\mathbf{4}$ - relevante & Pouca & 1 & $0,4 \%$ \\
\hline $\mathbf{4}$-relevante & Alta & 41 & $16,9 \%$ \\
\hline $\mathbf{4}$ - relevante & Extremamente alta & 10 & $4,1 \%$ \\
\hline $\mathbf{4}$ - relevante & Moderada & 16 & $6,6 \%$ \\
\hline $\mathbf{4}$ relevante & Nenhuma & 1 & $0,4 \%$ \\
\hline $\mathbf{4}$ - relevante & Pouca & 7 & $2,9 \%$ \\
\hline $\mathbf{5}$ - Extremamente relevante & Alta & 79 & $32,6 \%$ \\
\hline $\mathbf{5}$ - Extremamente relevante & Extremamente alta & 30 & $12,4 \%$ \\
\hline $\mathbf{5}$ - Extremamente relevante & Moderada & 18 & $7,4 \%$ \\
\hline $\mathbf{5}$ - Extremamente relevante & Pouca & 3 & $1,2 \%$ \\
\hline Total Geral & & 242 & $100 \%$ \\
\hline
\end{tabular}

Fonte: Elaboração própria.

De acordo com o previsível, o grupo de inquiridos que considera "Extremamente Relevante" a utilização do telemóvel durante a viagem turística integra o que considera uma influência "Extremamente alta", com 12,4\% (30 respostas); e os que consideram uma influência "Alta", com 32,6\% (79 respostas).

No grupo de inquiridos que consideram "Relevante", a utilização do telemóvel durante a viagem turística integra os que consideram uma influência "Alta", com 16,9\% (41 respostas). A partir da Figura 12, também se pode constar que quem não considera relevante o uso de telemóvel também não considera relevante a influência dos comentários durante uma viagem turística. 
Rev.Tur., Visão e Ação, v21, n3, p265-290, Set./Dez. 2019 - Balneário Camboriú, Santa Catarina, Brasil

Figura 11 - Qual a influência da utilização de comentários durante uma viagem turística por média de idade

\begin{tabular}{|c|c|c|c|c|c|}
\hline Média de Idade & -15 - Extremamente alta & 4 - Alta & 3 - Moderada & 2 - Pouca & Total Geral \\
\hline 5 - Extremamente relevante & 33,3 & 31,4 & 33,7 & 21,7 & 32,0 \\
\hline 4 - relevante & 28,3 & 32,7 & 30,6 & 37,3 & 32,1 \\
\hline 3 - Neutro & 23,0 & 29,4 & 33,5 & 22,0 & 30,5 \\
\hline 2 - Pouco relevante & 21,0 & 32,0 & 51,0 & 70,0 & 45,0 \\
\hline 1 - Nenhuma relevância & & & 39,0 & & 39,0 \\
\hline Total Geral & 31,6 & 31,5 & 33,4 & 34,8 & 32,1 \\
\hline
\end{tabular}

Fonte: Elaboração própria.

Na Figura 11, a média de idade dentro de cada grupo de inquiridos, tendo em consideração o cruzamento entre a relevância do smartphone e a importância dos comentários, verificou-se que vai aumentando a idade consoante vai diminuindo a influência da utilização dos comentários. $\bigcirc$ grupo dos que consideram "Extremamente relevante" a utilização do telemóvel apresenta uma média de idades à volta dos 30 anos, com exceção dos que atribuem pouca importância aos comentários, que pertencem a uma média de idade de 20 anos. Um dos motivos que pode estar relacionado com estes resultados é a geração a que estes turistas pertencem, pois os primeiros pertencem à geração dos millennials e os segundos à geração dos centennials.

Outro objetivo da investigação foi perceber "Qual a principal ação que realiza com recurso aos smartphones durante a viagem?", cujas respostas podem ser analisadas na Figura 12.

Figura 12 - Qual a principal ação que realiza com recurso aos smartphones durante a viagem?

\begin{tabular}{|l|r|r|}
\hline $\begin{array}{l}\text { Qual a principal ação que realiza com recurso aos smartphones } \\
\text { durante a viagem? }\end{array}$ & $\begin{array}{c}\text { № de } \\
\text { Inquiridos }\end{array}$ & $\begin{array}{c}\text { № de Inquiridos } \\
\text { (\%) }\end{array}$ \\
\hline Comunicar & 56 & 116 \\
\hline Consultar informações sobre o destino e/ou locais de interesse & 58 & $4 \%$ \\
\hline Efetuar reservas & 10 & $24,9 \%$ \\
\hline Fotografias, opinião, entre outros & 2 & $24,0 \%$ \\
\hline Pagamento de serviços da viagem & 242 & $0,1 \%$ \\
\hline Total Geral & $100,0 \%$ \\
\hline
\end{tabular}

Fonte: Elaboração própria.

De acordo com as respostas, a principal ação realizada durante a viagem é "Consultar informações sobre o destino e/ou locais de interesse", com 47,9\%; correspondente a 116 respostas; seguindo-se "Efetuar reservas, com 23,9\%, que corresponde a 58 respostas; "Comunicar", com 23,1\%, que corresponde a 56 respostas. De destacar que "Fotografias, opiniões, entre outros" não é a principal atividade que realizam com recurso à tecnologia móvel. 
Quanto à rede social mais utilizada, destacam-se o TripAdvisor, com 58,3\% (141 respostas); o Facebook, com 19,8\% (48 respostas); o Google+, com 15,3\% (37 respostas); e o Youtube, com 3,3\% (8 respostas), em que o TripAdvisor é, inegavelmente, a maior fonte de consultas, tal como apresentado na Figura 13, e do género feminino, tal como apresentado na Figura 14.

Figura 13 - Rede social mais utilizada pelos inquiridos.

\begin{tabular}{|l|r|r|}
\hline Qual a rede social que mais utiliza ao planear uma viagem? & $\begin{array}{c}\text { No de } \\
\text { Inquiridos }\end{array}$ & No de Inquiridos (\%) \\
\hline TripAdvisor & 141 & $58,3 \%$ \\
\hline Facebook & 48 & $19,8 \%$ \\
\hline Google+ & 37 & $15,3 \%$ \\
\hline Youtube & 8 & $3,3 \%$ \\
Momondo, Booking & 1 & $0,4 \%$ \\
OTA's & 1 & $0,4 \%$ \\
\hline Triposo & 1 & $0,4 \%$ \\
Whatsapp & 1 & $0,4 \%$ \\
Nenhuma & 4 & $1,7 \%$ \\
\hline Total Geral & 242 & $\mathbf{1 0 0 , 0} \%$ \\
\hline
\end{tabular}

Fonte: Elaboração própria.

Figura 14 - Rede social mais utilizada por género.

\begin{tabular}{|c|c|c|c|}
\hline $\mathrm{N}^{\mathrm{o}}$ de Inquiridos (\%) & & Género $=$ & \\
\hline Qual a rede social que mais utiliza ao planear uma viagem? & \pm & Feminino & Masculino \\
\hline TripAdvisor & & $75,9 \%$ & $24,1 \%$ \\
\hline Facebook & & $77,1 \%$ & $22,9 \%$ \\
\hline Google+ & & $81,1 \%$ & $18,9 \%$ \\
\hline Youtube & & $75,0 \%$ & $25,0 \%$ \\
\hline
\end{tabular}

Fonte: Elaboração própria.

A procura de informação sobre o destino e/ou locais de interesse, tal como referido no trabalho de Gretzel (2011), é a atividade realizada mais vezes durante a viagem, sendo o TripAdvisor a rede mais consultada, o que confirma o interesse na procura de informação on-line.

A relevância da utilização de smartphones durante uma viagem turística é comprovada, tal como refere Wang et al. (2016), e os comentários de viagem colocados e consultados na internet continuam a ser a principal ação realizada pelos turistas durante a sua viagem por meio de dispositivos móveis, o que vai ao encontro do trabalho de Xiang et al. (2015), tal como apresentam a Figura 15 e a Figura 16. 
Rev.Tur., Visão e Ação, v21, n3, p265-290, Set./Dez. 2019 - Balneário Camboriú, Santa Catarina, Brasil

Figura 15 - Relevância do uso de smartphone por influência dos comentários presentes nas redes sociais.

\begin{tabular}{|c|c|c|c|c|c|c|c|}
\hline Relevância do uso de smartphones & -1 & Influência dos comentários $-\downarrow$ & Facebook & Google+ & TripAdvisor & Youtube & Outra \\
\hline \multicolumn{8}{|l|}{ 5 - Extremamente relevante } \\
\hline 5 - Extremamente relevante & & 5 - Extremamente alta & $0,8 \%$ & $1,2 \%$ & $9,8 \%$ & $0,0 \%$ & $0,4 \%$ \\
\hline 5 - Extremamente relevante & & 4 - Alta & $5,3 \%$ & $6,1 \%$ & $20,1 \%$ & $0,8 \%$ & $0,4 \%$ \\
\hline 5 - Extremamente relevante & & 3 - Moderada & $3,3 \%$ & $0,4 \%$ & $2,5 \%$ & $0,0 \%$ & $1,6 \%$ \\
\hline 5 - Extremamente relevante & & 2 - Pouca & $0,4 \%$ & $0,4 \%$ & $0,0 \%$ & $0,4 \%$ & $0,0 \%$ \\
\hline \multicolumn{8}{|l|}{$\exists 4$ - Relevante } \\
\hline 4 - Relevante & & 5 - Extremamente alta & $0,8 \%$ & $1,2 \%$ & $2,0 \%$ & $0,0 \%$ & $0,0 \%$ \\
\hline 4 - Relevante & & 4 - Alta & $2,0 \%$ & $2,9 \%$ & $10,2 \%$ & $1,2 \%$ & $0,4 \%$ \\
\hline 4 - Relevante & & 3 - Moderada & $1,6 \%$ & $0,4 \%$ & $4,1 \%$ & $0,0 \%$ & $0,8 \%$ \\
\hline 4 - Relevante & & 2 - Pouca & $0,0 \%$ & $1,6 \%$ & $1,2 \%$ & $0,0 \%$ & $0,0 \%$ \\
\hline \multicolumn{8}{|l|}{$\exists 3$ - Neutro } \\
\hline 3 - Neutro & & 5 - Extremamente alta & $0,0 \%$ & $0,0 \%$ & $0,4 \%$ & $0,0 \%$ & $0,0 \%$ \\
\hline 3 - Neutro & & 4 - Alta & $0,8 \%$ & $0,8 \%$ & $2,9 \%$ & $0,8 \%$ & $1,6 \%$ \\
\hline 3 - Neutro & & 3 - Moderada & $0,0 \%$ & $0,4 \%$ & $4,1 \%$ & $0,0 \%$ & $0,4 \%$ \\
\hline 3 - Neutro & & 2 - Pouca & $0,0 \%$ & $0,0 \%$ & $0,0 \%$ & $0,0 \%$ & $0,4 \%$ \\
\hline \multicolumn{8}{|l|}{$\Xi 2$ - Pouco relevante } \\
\hline 2 - Pouco relevante & & 5 - Extremamente alta & $0,0 \%$ & $0,0 \%$ & $0,4 \%$ & $0,0 \%$ & $0,0 \%$ \\
\hline 2 - Pouco relevante & & 4 - Alta & $0,0 \%$ & $0,0 \%$ & $0,0 \%$ & $0,0 \%$ & $0,4 \%$ \\
\hline 2 - Pouco relevante & & 3 - Moderada & $0,0 \%$ & $0,8 \%$ & $0,0 \%$ & $0,0 \%$ & $0,0 \%$ \\
\hline 2 - Pouco relevante & & 2 - Pouca & $0,0 \%$ & $0,0 \%$ & $0,4 \%$ & $0,0 \%$ & $0,0 \%$ \\
\hline \multicolumn{8}{|l|}{$\exists 1$ - Nenhuma relevância } \\
\hline 1 - Nenhuma relevância & & 3 - Moderada & $0,4 \%$ & $0,0 \%$ & $0,0 \%$ & $0,0 \%$ & $0,0 \%$ \\
\hline
\end{tabular}

Fonte: Elaboração própria.

Na Figura 15, é efetuada a análise da relevância do uso de smartphones por influência dos comentários, tendo em consideração a rede social mais utilizada para planear as suas viagens, onde se destaca o TripAdvisor com as percentagens mais elevadas, para quem considera o uso de smartphone "extremamente relevante" e "relevante". Nos inquiridos que não atribuem relevância ao uso de smartphone, ou seja, "neutro", "pouco relevante" e "nenhuma relevância", a influência dos comentários apresenta valores muito baixos, tal como seria de esperar.

Para analisar a relevância do uso de smartphone, na Figura 16 apenas foram considerados os inquiridos que responderam "extremamente relevante" e "relevante". No grupo dos "extremamente relevante", destacam-se as ações de consultar informação sobre o destino e/ou os locais de interesse nas redes socais Facebook e Google +, no TripAdvisor a ação mais realizada é a consulta de informação, sendo esta ação a que apresenta uma taxa mais elevada de resposta $(22,2 \%)$. 
Figura 16 - Relevância do uso de smartphone, tendo em consideração a principal ação realizada com recurso ao dispositivo durante as viagens e a rede social que mais utilizam para planear as suas viagens.

\begin{tabular}{|c|c|c|c|c|c|}
\hline \multirow{2}{*}{$\begin{array}{l}\text { Relevância do uso de } \\
\text { smartphones }\end{array}$} & Qual a principal ação que realiza com recurso aos Smartphones & \multirow[t]{2}{*}{ Facebook } & \multirow[t]{2}{*}{ Google+ } & \multirow[t]{2}{*}{ TripAdvisor } & \multirow[t]{2}{*}{ Outra } \\
\hline & durante as suas viagens? & & & & \\
\hline \multicolumn{6}{|l|}{ E5 - Extremamente relevante } \\
\hline 5 - Extremamente relevante & Check-in, trocas de vouchers, entre outros & $0,97 \%$ & $0,00 \%$ & $0,97 \%$ & $0,00 \%$ \\
\hline 5 - Extremamente relevante & Compara preços e/ou verificar disponibilidade de alojamento & $0,48 \%$ & $0,97 \%$ & $2,42 \%$ & $0,48 \%$ \\
\hline 5 - Extremamente relevante & Comunicar & $1,45 \%$ & $0,48 \%$ & $3,38 \%$ & $0,48 \%$ \\
\hline 5 - Extremamente relevante & Consultar informações sobre o destino e/ou locais de interesse & $2,90 \%$ & $6,28 \%$ & $22,22 \%$ & $0,48 \%$ \\
\hline 5 - Extremamente relevante & Efetuar reservas & $0,48 \%$ & $0,00 \%$ & $0,97 \%$ & $0,48 \%$ \\
\hline 5 - Extremamente relevante & Fotografias, opinião, entre outros. & $5,31 \%$ & $1,93 \%$ & $7,73 \%$ & $1,93 \%$ \\
\hline 5 - Extremamente relevante & Pagamento de serviços da viagem & $0,00 \%$ & $0,00 \%$ & $0,48 \%$ & $0,48 \%$ \\
\hline \multicolumn{6}{|l|}{$\boxminus 4$ - Relevante } \\
\hline 4 - Relevante & Cancelar ou alterar reservas & $0,00 \%$ & $0,48 \%$ & $0,00 \%$ & $0,00 \%$ \\
\hline 4 - Relevante & Check-in, trocas de vouchers, entre outros & $0,00 \%$ & $0,00 \%$ & $0,97 \%$ & $0,00 \%$ \\
\hline 4 - Relevante & Compara preços e/ou verificar disponibilidade de alojamento & $0,00 \%$ & $0,48 \%$ & $0,48 \%$ & $0,48 \%$ \\
\hline 4 - Relevante & Comunicar & $0,97 \%$ & $0,00 \%$ & $1,45 \%$ & $0,00 \%$ \\
\hline 4 - Relevante & Consultar informações sobre o destino e/ou locais de interesse & $1,93 \%$ & $3,86 \%$ & $9,66 \%$ & $1,45 \%$ \\
\hline 4 - Relevante & Efetuar reservas & $0,00 \%$ & $0,00 \%$ & $0,00 \%$ & $0,48 \%$ \\
\hline 4 - Relevante & Fotografias, opinião, entre outros. & $2,42 \%$ & $1,93 \%$ & $8,21 \%$ & $0,48 \%$ \\
\hline 4 - Relevante & Pagamento de serviços da viagem & $0,00 \%$ & $0,48 \%$ & $0,00 \%$ & $0,00 \%$ \\
\hline
\end{tabular}

Fonte: Elaboração própria.

No grupo dos "relevante", referente à importância do uso de smartphone durante a viagem, os resultados são semelhantes ao grupo anterior, em que as ações mais realizadas são a consulta de informação sobre o destino e/ou locais de interesse e por fotografias e comentários. Destaca-se ainda que, na rede social Facebook e deste grupo, a ação mais realizada é de procurar por fotografias e comentários, não sendo esta plataforma destinada à procura de informações sobre o destino.

Deste modo, pode-se concluir que os smartphones desempenham um papel muito importante para os turistas durante a sua viagem, cuja principal utilização é a consulta de informações sobre o destino e o TripAdvisor a rede social mais consultada.

Outra conclusão que pode ser extraída é que a maioria dos inquiridos já considera relevante a utilização destes dispositivos para a sua viagem, tal como referido na revisão de literatura, bem como a ação mais realizada é a consulta de informação sobre o destino, sobre pontos de interesse, fotografias, comentários e outras informações associadas ao local que pretende ou está a visitar.

Neste contexto, este estudo contribui para que os agentes do destino e as entidades públicas ou privadas considerem que toda divulgação, promoção e campanhas publicitárias sobre a região deverão em primeiro lugar privilegiar o meio de comunicação por meio dos dispositivos móveis, atribuindo atenção às plataformas de redes sociais, principalmente o Facebook, TripAdvisor e Google+, o que contribuir para aumentar a interação com empresas turísticas e o relacionamento com a família e os amigos durante as férias.

A interação com as empresas e a importância da utilização de smartphones contribuem para o desenvolvimento de práticas de comércio on- 
Rev.Tur., Visão e Ação, v21, n3, p265-290, Set./Dez. 2019 - Balneário Camboriú, Santa Catarina, Brasil

line, mesmo quando o turista está no local onde usufrui das suas férias, o que tem contribuído para a alteração do comportamento do consumidor enquanto se encontra no destino turístico, o que acrescenta valor à sua experiência turística (Lemon \& Verhoef, 2016).

\section{CONSIDERAÇÕES FINAIS}

A utilização dos smartphones durante a viagem é de grande interesse e relevância, pois a busca do ser humano por respostas rápidas no mundo globalizado levou ao desenvolvimento de ferramentas que facilitam a vida e automatizam as tarefas e os processos. Neste contexto, a utilização deste dispositivo permite ir ao encontro da satisfação dos desejos do turista para procurar no imediato uma resposta às suas necessidades, procurar por informação, um restaurante ou um evento (Lemon \& Verhoef, 2016). Uma das maiores expressões dessa mudança é a internet. Sua constante evolução transformou a forma como as pessoas procuram informações, se relacionam, trabalham, estudam e vivem (Castells, 1997).

Considerada por muitos uma das maiores invenções da humanidade, a internet permite que pessoas, países, empresas, etc. se conectem com o mundo com baixo custo e facilidade na interação. A velocidade das informações, o acesso ao que ocorre no mundo, as mudanças culturais, o crescimento econômico e o progresso da tecnologia consolidaram a mesma como uma ferramenta fundamental, que se mostra cada vez mais presente em todas as áreas, inclusive no turismo (Xiang et al., 2015a; Xiang et al., 2015b). Vive-se em um mundo cada vez mais uniformizado e, no turismo, a autenticidade é de grande importância (Vannini \& Williams, 2016). Os dispositivos móveis vieram para ficar e cada vez mais estão mais presentes nas diversas etapas da organização da viagem, na compra, na experiência turística como um todo (Wang et al., 2016). $\mathrm{Na}$ investigação realizada, verificou-se que a maioria dos inquiridos considera relevante a utilização de smartphones e que os comentários existentes no meio digital influenciam os viajantes e contribuem para a experiência turística, principalmente os que se encontram no TripAdvisor.

O smartphone é cada vez mais um complemento de viagem, sendo considerando um acessório essencial. Este estudo permitiu concluir que os turistas recorrem a este tipo de dispositivo para consultar informação sobre os destinos e os pontos de interesse existentes ao longo do percurso da sua viagem, bem como recorrem a esta tecnologia para efetuar reservas e comunicar com amigos, familiares e outros viajantes, tal no estudo de Braga (2015), Wang et al. (2012; 2016), Yu et al. (2018), entre outros. Uma das redes sociais mais utilizada é o TripAdvisor, seguindo-se o Google+ e o Facebook, para consultar informação sobre destinos turistiscos e seus pontos de interesse, bem como fotografias e comentários, tal como no estudo de Xiang e Gretzel (2010). Este estudo permitiu concluir que a partilha de fotografias e de opiniões não é a atitude mais praticada, quando os turistas recorrem ao smartphone, mas antes a procura de 
informações sobre o local onde se encontram, sendo relevante para um estudo futuro a análise do que é realizado no local turístico, tendo em consideração o contexto local em que o turista se encontra, tal como considerado no estudo de Dickinson et al. (2014).

A utilização do smartphone durante a viagem, e não só, tem contribuído para alterar o comportamento do consumidor, que pode efetuar reservas online, bem como permite comunicar e interagir com a comunidade residente, a família e os amigos, o que tudo contribui para criar e, guardar e partilhar memórias que acrescentam valor à sua experiência pessoal e turística (Lemon \& Verhoef, 2016). Os resultados obtidos confirmam que os smartphones são amplamente utilizados durante as viagens turísticas, apresentam as funcionalidades mais utilizadas e apontam novas oportunidades de interação entre os consumidores, as empresas e os destinos turísticos.

A presente investigação é um ponto de partida sobre a importância da utilização do smartphone para a realização de uma viagem turística. Em termos de trabalho futuro, estão previstos o aprofundar dos conceitos apresentados e a elaboração de um questionário que permita aferir mais fatores que contribuem para a experiência associada à viagem turística, tendo em consideração as vertentes associadas ao entretenimento, ao escapismo, à aquisição de conhecimento sobre o destino e a estética, tal como previsto na "economia das experiências" (Pine \& Gilmore, 1999).

\section{ACKNOWLEDGES}

This paper is financed by National Funds provided by FCT - Foundation for Science and Technology through project CINTURS (UID/SOC/04020/2019) and project CEFAGE (UID/ECO/04007/2019).

\section{REFERÊNCIAS}

Amadeus (2015). Future Traveller Tribes 2030 Building a more rewarding journey. Disponível em: https://amadeus.com/documents/en/blog/pdf/2015/07/amadeus-travellertribes-2030-airline-it.pdf

Arup (2013). The Smart City Market Opportunities for the UK. The Department of Business Innovation \& Skills. Arup. Disponível em: http://bluegreenuk.com/references/ government_institutional/bis-research-paper-smart-city-market-opportunties-uk. pdf

Biz, A. A., Neves, A. J., \& Bettoni, E. M. (2014). O comportamento dos consumidores turísticos no uso da telefonia móvel. Caderno Virtual de Turismo, 14(1).

Braga, G.H. (2015). Brasileiros estão entre os que mais usam smartphone para viajar. Disponível em: http://www.turismo.gov.br/ultimas-noticias/5223-brasileirosest\%C3\%A3o-entre-os-que-mais-usam-smartphone-para-viajar.html 
Rev.Tur., Visão e Ação, v21, n3, p265-290, Set./Dez. 2019 - Balneário Camboriú, Santa Catarina, Brasil

Bremner, C. \& Nelson, P. (2015). World Travel Market Global Trends Report 2015 in WTM London.Disponívelem:http://news.wtmlondon.com/wp-content/uploads/2015/11/ Global-Trends-Report-2015.pdf

Castells, M. (1997). End of Millennium: The Information Age: Economy, Society and Culture. Blackwell Publishers, Inc.

Christino, J.M.M., Silva, T.S., Cardozo, E.A.A., \& Lopes, A.G.R. (2019). Adoção de plataformas on-line de hospedagem compartilhada: um estudo do comportamento de uso do Airbnb. Turismo-Visão e Ação, 21 (1), 165-185.

Cruz Vareiro, L. M., \& de Sousa Pinheiro, T. C. (2017). A Influência da Crise na Escolha pelo Consumidor entre Agências de Viagens ou Operadores On-Line. Turismo-Visão e Ação, 19(2), 220-243.

Oliveira, M. P. de, \& Malagolli, G. A. (2016). O Impacto da Tecnologia da Informação na Evolução dos Serviços Bancários. Revista Interface Tecnológica, 13(1), 39-52.

Dias, P. (2007). O impacto do telemóvel na sociedade contemporânea: panorama de investigação em Ciências Sociais. Comunicação \& Cultura, 3, 77-96.

Dickinson, J. E., Ghali, K., Cherrett, T., Speed, C., Davies, N., \& Norgate, S. (2014). Tourism and the smartphone app: Capabilities, emerging practice and scope in the travel domain. Current Issues in Tourism, 17(1), 84-101.

Dubbi (2019). Dubbi. Disponível em: https://www.dubbi.com.br/

E-Commerce News (2012). Mulheres são mais engajadas que homens no facebook. Disponível em: https://www.internetinnovation.com.br/blog/mulheres-sao-maisengajadas-que-homens-no-facebook-diz-giuliana-flores/

Françozo, M. T., \& De Mello, N. C. (2016). Influência dos Aplicativos de Smartphones para Transporte Urbano no Transito. In 7th Luso-Brazilian Congress for Urban, Regional, Integrated and Sustainable Planning. Maceio.

Freitas, H., \& Moscarola, J. (2002). Gestão da Informação - Da Observação à Decisão: Métodos de Pesquisa e de Análise Quantitativa de Dados. Eletrônica, 1(1).

Google Travel Study (2014). The 2014 Traveler's Road to Decision. Disponível em: http:// storage.googleapis.com/think/docs/2014-travelers-road-to-decision_research_ studies.pdf

Gretzel, U. (2011). Intelligent systems in tourism: A social science perspective. Annals of tourism research, 38(3), 757-779.

Guimarães, A. S., \& Borges, M. P. (2008). E-turismo: Internet e Negócios do Turismo. São Paulo: Cengage Learning.

Hitwise (2016). What do consumers search for from their smartphones and tablets? Hitwise, a division of connexity. Disponível em: www.connexity.com

Hitwise (2017). Travel in 2017. A Digital Marketing Perspective. Hitwise, a division of connexity. Disponível em: www.connexity.com 
Ibope Nielsen Online (2015). Quem mais acessa a internet pelo smartphone?. Disponível em: $\quad$ https://www.nielsen.com/br/pt/insights/news/2015/Quem-mais-acessa-ainternet-pelo-smartphone.html

Jenkins, H. (2008). Cultura da convergência. São Paulo: Aleph.

Kim, D. Y., Park, J., \& Morrison, A. M. (2008). A model of traveller acceptance of mobile technology. International Journal of Tourism Research, 10(5), 393-407.

Lemon, K. N., \& Verhoef, P. C. (2016). Understanding customer experience throughout the customer journey. Journal of marketing, 80(6), 69-96.

Lemos, A. (2017). Celulares, funções pós-midiáticas, cidade e mobilidade. Revista Brasileira de Gestão Urbana, 2(2), 155-166.

Loller, B. (2012). The user experience revolution on mobile travel services: from mobile-first to mobile-only. Disponível em: https://www.tnooz.com/article/the-user-experiencerevolution-on-mobile-travel-services-from-mobile-first-to-mobile-only/

Ministério do Turismo (2015). Brasileiros estão entre os que mais usam smartphone para viajar. Disponível em: http://www.turismo.gov.br/ultimas-noticias/5223-brasileirosest\%C3\%A3o-entre-os-que-mais-usam-smartphone-para-viajar.html

Net//Scope (2018). Net//Marktest. Disponível em: http://net.marktest.pt/netscope/

Parasuraman, A., \& Colby, C. L. (2002). Marketing para produtos inovadores: como e por que seus clientes adotam tecnologia. Porto Alegre: Bookman.

Pegn (2016). Informação obtida em artigo online publicado na Revista Pequenas Empresas \& Grandes Negócios. Disponível em: Disponível em: http://revistapegn. globo.com/Banco-de-ideias/Diversao-e-turismo/noticia/2016/03/7-tendenciaspara-quem-deseja-empreender-no-setor-de-turismo.html

Pereira, A. T., DosSantos, E. S., Merino, E. A., Braviano, G., \& Colusso, L. F. (2018). A Mobilidade e o ciberespaço: explorando e interagindo nas cidades contemporâneas. DAPesquisa, 7(9), 486-497.

Pine, J., \& Gilmore, J. (1999). The experience economy. Boston: Harvard Business School Press.

Prado A. (2018). Viagens na Era da Assistência: os consumidores querem ajuda. Cadê sua marca nessa hora?. Disponível em: https://www.thinkwithgoogle.com/intl/ pt-br/tendencias-de-consumo/viagens-na-era-da-assistencia-os-consumidoresquerem-ajuda-cade-sua-marca-nessa-hora/

Rose, N. (2011). The always-connected traveller: How mobile will transform the future of air travel. Travel Tech Consulting Inc, 1-39.

Santos, M. \& Ramos, I (2009). Business Intelligence. Lisboa: FCA editora.

Torres, R. (2018). How to win travelers in the age of assistance. Disponivel em: https:// www.thinkwithgoogle.com/consumer-insights/age-of-assistance-travel-marketing/

Travel Tech Consulting (2019). Travel Industry Segments. Disponível em: https://www. traveltechnology.com/ 
Rev.Tur., Visão e Ação, v21, n3, p265-290, Set./Dez. 2019 - Balneário Camboriú, Santa Catarina, Brasil

Trovo, B. P., Artero, A. O., Piteri, M. A., \& da Silva, F. A. (2014, July). Compartilhamento de Informações de Trânsito Utilizando Smartphones. In Colloquium Exactarum (Vol. 6, No. 2).

Turismo 2020 (2015). Turismo 2020 Cinco princípios para uma ambição. Turismo de Portugal. Disponível em: http://www.turismodeportugal.pt/PORTUGU\%C3\%8AS/ TURISMODEPORTUGAL/DESTAQUE/Documents/turismo-2020-cinco-principios-parauma-ambicao.pdf

Tussyadiah, I. P., \& Fesenmaier, D.R. (2009). Mediating Tourist Experiences: Access to Places via Shared Videos. Annals of Tourism Research, 36 (1), 24-40.

Ugarkar, J. (2010). Essentials of telecommunications management: a simple guide to understanding a complex industry. AuthorHouse.

Vannini, P., \& Williams, J. P. (2016). Authenticity in culture, self, and society. In Authenticity in culture, self, and society (pp. 17-34). Routledge.

Veiga, C., Santos, M., Águas, P., \& Santos, J. (2017). Are millennials transforming global tourism? Challenges for destinations and companies. Worldwide Hospitality and Tourism Themes, 9(6), 603-616.

Wang, D., Park, S., \& Fesenmaier, D. R. (2012). The role of smartphones in mediating the touristic experience. Journal of Travel Research, 51 (4), 371-387.

Wang, D., Xiang, Z., \& Fesenmaier, D. R. (2016). Smartphone use in everyday life and travel. Journal of travel research, 55(1), 52-63.

Waze (2019). Waze. Disponível em: https://www.waze.com

Xiang, Z., \& Gretzel, U. (2010). Role of social media in online travel information search. Tourism management, 31 (2), 179-188.

Xiang, Z., Magnini, V. P., \& Fesenmaier, D. R. (2015a). Information technology and consumer behavior in travel and tourism: Insights from travel planning using the internet. Journal of Retailing and Consumer Services, 22, 244-249.

Xiang, Z., Wang, D., O'Leary, J. T., \& Fesenmaier, D. R. (2015b). Adapting to the internet: trends in travelers' use of the web for trip planning. Journal of Travel Research, 54(4), 511-527.

Yu, X., Anaya, G. J., Miao, L., Lehto, X., \& Wong, I. A. (2018). The impact of smartphones on the family vacation experience. Journal of Travel Research, 57(5), 579-596.

\section{CONTRIBUIÇÕES DE CADA AUTOR:}

JULIANA ROSSI: Fundamentação teórica, pesquisa de campo, desenvolvimento e análise dos resultados.

CÉLIA M.Q. RAMOS: Fundamentação teórica, estruturação, análise dos resultados e revisão. 